\title{
The View from Within: \\ Design's Voyage to Get a Seat at the Strategy Table
}

\author{
BOZTEPE Suzan ${ }^{\mathrm{a}}$ \\ a Malmö University \\ * Corresponding author e-mail: suzan.boztepe@mau.se \\ doi: $10.21606 / \mathrm{dma} .2017 .398$
}

\begin{abstract}
It is often argued that design serves as an effective change agent in strategy formation. However, the question of how this actually occurs remains largely unexplored. Through case studies of five design consulting firms in Denmark, this paper examines how design gets involved in the making of strategy. The findings show that there are at least two paths to strategy-level work: First, design works its way to strategizing through repeated client engagement and trust building. That is, design consulting firms work with the same client over a long period of time, they gain trust of their clients, so the complexity and strategic importance of their deliverables gradually increase. Second, design consulting firms use human-centered approach as a means for reviewing the business strategy of their clients. That is, user research brings user needs, problems and opportunities into focus, which, in turn, paves the way for strategy-level discussions and solution seeking. Each path is discussed in terms of issues in design management, including, but not limited to, design activities, competence building in design firms and organizational structures.
\end{abstract}

strategy; strategic design; design consulting firms; design management

\section{Introduction}

Design has always been associated with the physical outcomes of its work-products, graphics, interiors, etc. However, it has been more and more involved in addressing a broad range of complex organizational, social and even political issues. As a result, new forms of design, where the subject of design is no longer the physical object only, but also the organization or even the society itself, have emerged such as service design, strategic design, transformation design, and design of governance. Companies today are turning to design to figure out not only how to do better products but also for what to do next, or how to create an innovative organizational culture. These are questions which have long been reserved for strategic management consulting firms only. However, as the conventional management solutions fall short to address today's sticky problems at organizational and societal levels, design has gained growing attention. This interest is evidenced, if nothing else, by 
an unprecedented increase in design-related coverage in the business media over the last decade (e.g., Brown \& Martin, 2015; Kolko, 2015) as well as the trend among strategic management consulting firms to add design capabilities to their portfolios-typically through acquisition of design firms. For example, the first strategic design consulting firm, Doblin Group, has become part of Monitor, and then of Deloitte Consulting. Accenture acquired service design company, Fjord, and McKinsey \& Company bought Lunar. At the same time, many design consulting firms (DCFs) have been repositioning themselves as strategic design consulting firms or innovation consultants. Despite the interest, however, we do not know how this shift actually works in reality. For example, according to the Danish Design Center's recent survey with 805 Danish companies, $90 \%$ of the respondents that perceivably worked with design at a strategic level reported a positive influence on their bottom line (Danish Design Center, 2016). However, the same report also showed that only $13 \%$ of the companies supposedly employed design at a strategic level. Why would there be such a gap between the hype and the reality? One reason perhaps is that employing design strategically is nothing but easy. Due to its capacity to disrupt business as usual, design is often faced with stiff resistance within the organization (see Brown \& Martin, 2015). If this is the case, then how will design get a seat in the table? This paper aims to address this issue by examining data from five DCFs in Denmark which have strategy- or policy-level engagements with their clients. It looks particularly at the path to strategic work, and how DCFs themselves have transformed to deal with the evolving nature of their businesses.

\section{Expansion of Design}

The expansion of design is typically described in three- or four-stage models or frameworks (Buchanan, 2001; Danish Design Center, 2001; Gardien, Djajadiningrat, Hummels, \& Brombacher, 2014). These suggest an increased complexity as well as a shift of focus of design activities from objects towards strategic problem solving. Buchanan (2001), for example, was the first to point to the shift of focus in design. In his four orders of design, he explained that design evolved from symbolic and visual to design of material objects, and from there to strategic planning and systemic integration. Similar company-specific models and frameworks have been utilized to explain the progression of design activities. The best-known example is perhaps the so-called design staircase, introduced by the Danish Design Center (2001), where the bottom step is the lack of design, followed by design as crafting, then by design as process, and finally by design as strategy. Using ladder as a metaphor, however, may not be the best way to describe the evolution of design as multiple design practices continue to co-exist side by side, even within the same organization (Heskett, 2017). Thus, rather than linear progression from one stage to another, it would be safer to talk about the expansion of the focus of design-be it within a company or as a discipline.

The expansion of design's focus cannot be considered independently from the realities of the context in which it operates. Design has always been intertwined with its economic, technological, social and cultural environment (Heskett, 1985). Taking a political economy point of view, Julier (2017) attributed design's expansion to be a response to the shifts in the neoliberal capitalism and its changing notions of value creation. For example, in the early days of the neoliberalism, the focus on deregulation has put great emphasis on competition. This, in turn, created increased design focus on branding, portfolio development, and systemic integration of design elements for differentiation. Most recently, neoliberalization has led to drastic shrinking of state functions as a result of privatizations and outsourcing, eventually resulting in austerity measures. In the current period of austerity, Julier wrote, design has responded by taking a social turn. And, it did so in two ways: First, by designing more cost-efficient and human-centered government services, and second, by aligning with civil society that aims to fill the gap created due to shrinking government through community work, alternative economies, etc. Changes in the technological context have similarly forced design to adapt (Norman, 2016). The introduction of computers, communication networks, and other technologies created new spaces for design which called for new knowledge and competencies. As 
everyday devices became more and more complex, design had to find ways of addressing issues, such as usability and experience.

What enabled design to adapt so well to the changing environment is the deeply rooted idea that design is not bound to specific tangible outcomes and that everything may be the subject of design: "Increasingly there has been a tendency to think of policies, institutions, and behavior itself, as objects of design," Schön once wrote (1983, p. 77). Similarly, Simon (1969) believed that design was core competency for all professions concerned with turning the existing situations to preferred one. And when asked about the boundaries of design during an interview, Charles Eames famously answered: "What are the boundaries of problems?" (Design Q\&A, 1972). This all-encompassing approach is based on a set of definitions of design which view design as a basic human capacity (Heskett, 2002), a way of thinking (Buchanan 1992; Cross, 1982; Brown 2009), a set of methods and tools (Jones, 1970) or an attitude, (Boland \& Collopy, 2004; Michlewski, 2015). The emphasis is on the ways of thinking and doing, as well as on the systemic, holistic thinking and integrative work of design. This somehow idealized view of the scope of design has enabled design to penetrate management as an approach which may be "at the core of effective strategy development, organizational change, and constraint-sensitive problem solving" (Boland \& Collopy, 2004, p. 17).

\section{Strategic Design}

The idea of design as a strategic tool in organizations dates back to the 1950s, when prominent designers such Donald Deskey and Raymond Lowey argued that design is a high-level planning activity, essential for business competitiveness (see Heskett, 2017). However, the research that views design as a strategic resource and a vehicle for change is relatively recent (e.g., Kotler \& Rath, 1984; Dumas \& Mintzberg, 1989; Squires \& Byrne, 2002; Lojacono \& Zaccai, 2004; Ravasi \& Lojacono, 2005; Gornik, 2006). This research borrowed from strategy theories to argue that design could be one source of strategic advantage (see Borja de Mozota, 2011). For example, many were inspired by Porter's (1980) positioning approach, which viewed strategy as achieving and sustaining competitive advantage through establishing a favorable position in industry vis-à-vis competitors by differentiation or low-cost (e.g., Blaich \& Blaich, 1993; Kotler \& Rath, 1984; Lorenz, 1986; Walsh, Roy, \& Bruce, 1988). They argued that by creating visually distinct products design achieves low cost and differentiation, and thus, competitive advantage. With the rise of the resource-based view (RBV)(e.g., Barney, 1991; Wernerfelt, 1984) and dynamic capabilities approach (DC) (e.g., Eisenhardt \& Martin, 2000; Teece, Pisano, \& Shuen, 1997), the attitude towards design's strategic contribution began to change. According to these two approaches, design as a single, visually differentiated product was not hard to imitate, and thus, could bring only a short-lived competitive advantage. Therefore, it could easily be dismissed as a source of strategy. Instead, RBV and DC viewed strategy as building and reconfiguring firm-specific resources and capabilities. This was essentially a shift of focus from design as creator of differentiated products to design as an organizational activity with its own systematic processes which could be ingrained into organizations and reused. For example, many claimed that designers push for a fresh thinking about innovation throughout the organization by the priorities they hold and the tools they use (e.g., Borja de Mozota \& Kim, 2009; Jevnaker, 1998; Svengren Holm, 2011). In this sense, it was argued, design became an organizational competence that may lead to sustained innovation, as opposed to delivering one-time creative outputs. Indeed, RBV and DC offered additional framework to explore design's strategic contribution.

Design's engagement with strategy occurs in multiple ways. For example, Boztepe (2016) illustrated that designers may be responsible for (1) redefining existing organizational strategies, (2) creating capabilities for sustained innovation, and (3) being directly involved in strategy formation through future planning. That is, they use design to set vision and direction for a company, as well as identify strategies for systemic innovations which are harder for competitors to replicate and which can lead to long-term competitive advantage. 
Designers' ability to engage in strategy problems have been attributed to the properties strategy and design share (see Liedtka, 2000; Martin, 2009; Simon, 1993). As with design, it is argued, strategy making is abductive in nature. That is, it is concerned with envisioning a desired future state, and creating a blueprint for turning it into reality. Also, the problems design and strategy deal with are of similar in nature: They are too sophisticated with multiple variables that cannot be resolved with statistical means alone. This particularly makes design's ways of dealing with wicked problems applicable to strategy making. Simon $(1993,1996)$, even suggested that strategizing is actually designing - the reason being that any management activity aims to create a new state for organizations, markets and even industries, and design is precisely concerned with the creation of new future states. In fact, just like Simon, early strategy researchers viewed strategy formation as a "creative act" (Christensen et al., 1982, p. 180) and an "imaginative identification of new possibilities" (Andrews, 1980, p. 59). Andrews even wrote that at "[t]he heart of the strategic process is the generation of alternatives-combining in new ways market opportunity, customer needs, and company capabilities" (p. 41). In search of greater control over the strategy formation process, however, strategic management later took a somewhat different direction, giving rise to approaches with more formalized processes and tools, employing rational decision-making and statistical means, such as the planning approach pioneered by Ansoff (1965). Strategy is created centrally, with a purpose to give direction to all business units within an organization, including design. As such, it is a deliberate planning activity that belongs to the upper management only. Design, according to this view, can merely be an implementer of strategy decisions in a top-down fashion.

The shift to formalized processes in strategic management was not without its criticisms though. For one thing, number crunching may fall short in helping companies answer the question of what direction an organization has to take and why (Simon, 1993; Mintzberg, 1994). Also, several researchers called into question the idea that strategy making may occur only as a result of a conscious process and only at the top of the organizational hierarchy. Drawing on the behavioral theory of the firm (Cyert \& March, 1992), they rejected the idea that senior management rationally analyzes the organizational context, then forms, chooses and imposes strategy, as it supposedly denies the realities of organizational dynamics (e.g., Cohen et al., 1972; Mintzberg, 1978). They put forward that strategy could also emerge incrementally, and even unintentionally, and that various organizational members could be involved in strategy formation. Of course, strategy formation is a much more complex phenomenon than the deliberate vs. emergent dichotomy dictates, and may occur anywhere between the two ends of the spectrum (see Levinthal, 2011; Mintzberg and Waters, 1985). Thus, any research on the design's work at strategic level should take into account that design could be engaged in strategy formation both as a part of an explicit strategizing process, or within the daily practices. If everyday actions of organizational members are part of the strategy formation, then how can we distinguish between strategic work and non-strategic one? When are designers' work strategic? Shivakumar (2014) considers decisions as strategic if they affect the company's degree of commitment and exert a significant influence on the scope of the firm. The degree of commitment is about the willingness of a company to take decisions that are difficult to reverse. The scope of the firm stands for the firm's choice of products, activities, markets, as well as its architecture and culture. Heskett (2017) similarly defined strategic design as having a company-wide impact and being engaged with innovative products and systems, rather than improvements of single products. In this study, therefore, I considered as strategic not only design work that was explicitly labelled as such, but also any design work that had a company-wide impact and effect on the client company's scope and commitment.

\section{Method}

The study involved case studies of five DCFs located in Denmark. They were (1) CPH Design, (2) Designit, (3) DN Group, (4) Red Associates, and (5) Seidenfaden Design Copenhagen. The 
participating firms ranged in size from 9 to $100+$ employees. While two of the firms had only one office, the other three had offices located both in and outside Denmark.

The primary data collection technique was a series of semi-structured interviews. Heskett's (2001) case study guidelines were adapted and used as a framework for the interviews. All interviews were conducted face-to-face on site. At least three interviews were conducted in each firm. The interviewees were partners, design managers, project managers, and designers. Each interview lasted 2 to 3 hours, depending on the interviewee's availability. Additional data consisted of archival information such as company publications, project documentations, media articles, and photos of products and of the workplace, etc. taken during visits. All interviews were tape-recorded and then transcribed. A total of 29 hours of interviews was recorded. The transcribed data was coded for categories, as identified in the case study guidelines. Specifically, I looked for cues as to how design appeared to function at strategy level. Then, patterns of practice across cases, if any, were identified. The question of how design functions at strategy level, including setting vision, distinctive market positioning, future planning, sustained company innovativeness was analyzed along with the management of design activities. Finally, based on the grounded descriptions of design practices and analyses, strategic practices and design functions of the participating DCFs were identified.

\section{The Path to Strategy-Level Work}

The participating DCFs appeared to operate at strategic and even organizational/social transformational levels. The work at this level was characterized by the use of design knowledge, skills, processes and tools to shape organizational positioning, build innovative capabilities in client organizations, or set future vision or direction (see Boztepe, 2016).

As it emerged from the data, DCFs got involved in strategy-level work in two distinct but related ways: (1) gradual expansion through repeated client engagement and trust building, and (2) humancentered design.

\subsection{Repeated Client Engagements and Trust Building}

Four of the DCFs initially started as product design firms. Over the years, however, they gradually expanded their services to include graphic design, advertising, branding, service design, user research and strategy design. The driving forces behind their expansion were their clients' demand for complementing products and services, and the firms' own desire to lock-in clients. DN Group's engagement with a Taiwanese client is a typical example: Initially, DN Group was contracted for design of individual products that would appeal to the European market. The client later wanted to have packages that communicated the product's identity, which, in turn, led to design of environments, etc. The complexity and the strategic importance of deliverables increased over time as trust had been built with the client. So, the work of DN Group shifted to aligning the design language across various touchpoints. Then, the company became more and more engaged with the question of what to do next, which led to portfolio management, competitive positioning, and even vision setting.

Expansion due to repeated client engagements and trust building may be said to occur in three phases: In the first phase, DCF is engaged in design of individual, differentiated products that supposedly help to reposition client's existing strategy or represent it in creative ways. This typically requires some commitment on the client's side but does not change the overall scope of the firm. Repeated satisfactory transactions make clients aware of the capabilities of design and help build trust. Developing relationships based on trust is central to any inter-firm collaboration. However, it becomes even more essential when it comes to design projects, due to high uncertainty and ambiguity surrounding the success of design outcomes (Alversson, 2011). Once trust is established, the volume and the frequency of collaboration between the DCF and its clientele increase, and the scope broadens. By now, clients are already familiar with what the design firm can do and how it 
works. Notice that the majority of the clients of the above-named DCFs were early adopters of design (Junginger, 2009), with limited or no in-house design resources.

In the second phase, the design work has an integrative nature, where each new project is treated as part of a larger system of integrated products, processes, services, environments, etc. This phase is motivated by client's desire to establish consistency across its various touchpoints. Design firms see this as an opportunity to establish a design language for their clients, and, in so doing, they secure longer-term accounts. More exploratory projects and user research become part of the work. As a good track record has already been established, clients are often more open to new ideas. Designers tend to act, among other things, as a source of procedural knowledge. During interviews, participants often referred to the importance of educating or teaching clients through doing. In the early stages of projects, they do this by sharing an initial set of principles, outlining the requirements for successful innovation, such as collaborative work and insights based on user research. When the project is underway, they do it by immersing clients in design work. Designit, for example, requires its clients to assign an employee as a dedicated team member, and expects him or her to actively participate in the design process. Typically, this employee is someone who is part of the client organization's innovation, design or product development unit. CPH Design trains its clients by conducting co-creation workshops, so to say, in which the client is expected to actively participate during ideation. The participants of these workshops include employees from the client organization, ranging from workers to top managers. The expectation is that the client will develop a high level of ownership and enthusiasm over the ideas developed but will also internalize the design process. As many interviewees noted, success depended on the extent to which designers achieved introducing the client team to the innovation process and persuading them to champion design.

In the third phase, design begins to get engaged with products and services that have an impact on the client's strategy, organizational and even social change. Also, projects aiming at building innovative competencies and culture within the client organization are typical. This phase may at first seem to be invisible, running in the form of "ongoing conversations," as defined by the founder of the DN Group. These conversations typically occur in-between projects and revolve around the question of what to do next. Therefore, they have a significant impact on the scope and the direction of the client: "The most important design work happens between projects," he noted. That is, the identification of future opportunities in fact takes place when the client is not officially receiving any consulting services. So, the strategic work remains invisible, and thus, the client ends up with receiving the service for free.

For some DCFs, strategy-level work is an inseparable part of their expanded service range. For example, Designit not only designed Novo Nordisk's NovoPen, but also was in charge of the product launch pack and user manuals in online and print versions. Designit later became part of envisioning their client's brand and communication strategy and devising their design policy. In more recent work with Novo Nordisk, they were involved in long-term vision setting and future scenario development. That is, they moved from design of product systems to devising design and brand strategies, and then to envisioning future directions for their client. In this phase, DCFs are able to influence both their clients' offerings and their ways of doing business. Building innovation capabilities within the client organization is carried out more explicitly. Thanks to repeated engagements, the clients have now developed some understanding of the design process and want to internalize design's innovation capabilities. All participating DCFs in my study were engaged in activities such as innovation training and design workshops to serve this purpose. In so doing, designers invested a significant amount of effort in developing custom training programs and tangible tools, such as templates, games, workbooks, etc. that supposedly facilitated client understanding of and immersion in the design process, even in the absence of designers. For example, CPH Design developed a deck of cards in order to support creative idea generation for one of its clients. This kind of tools, they believed, would help make the client organization employees' transition to the newly introduced ways of doing business less painful. 
Notice that the client companies in this phase consisted of organizations both with and without inhouse designers. The role of designers within the organization across clients with in-house designers, however, differed significantly. On the one side, there were designers who merely focused on typical design problems of product development and corporate identity, whereas, on the other, there were clients whose internal design teams were already working at the level of strategy. For the latter, working together with DCFs was a way of reinforcing their limited design resources and benefiting from DCFs' experience of working across industries. As noted by the design manager of a client company, a major medical firm, their work with the DCF helped them secure and even strengthen the in-house design team's position within the company. One reason was perhaps that DCFs communicated directly with the upper management, which, in turn, made design's capabilities more visible, and changed the expectation placed on the internal design team. It could also be the case that, thanks to working together with the DCF, certain skills and knowledge were transferred to the internal design team, which they then made use of when dealing with strategy-level issues.

For DCFs, the search for client lock-in and higher profits was a major driving force for the move towards a more strategic direction. At the same time, however, there was an almost naïve desire to create an impact. One partner at Designit said they were now so saturated, meaning they had no shortage of clients, that they selected only clients for more strategic engagements: "We want to be in projects that have an impact," he noted. This idea of impact was not limited to organizations they worked with. For example, one firm had self-initiated projects targeted towards creating social change and a sustainable future. These were projects typically about future scenarios. There was a high level of enthusiasm within the firm to partake in those projects. Such efforts served the purpose of projecting an image of being on the edge, showcasing design's future-making potential, and of course attracting similar projects.

The expansion in design is represented by an increased footprint in the client's value chain. That is, more activities across the value chain are covered by DCFs. This is achieved by horizontal value integration of DCFs, to which typically diverse design services are integrated. This, in turn, means the added competence of managing transdisciplinary teams. But DCFs differed in their approaches to how teams should be formed. In two firms, for example, the project was assigned to a team. In others, transdisciplinary teamwork applied in all projects from start to end, but the team composition changed over time. Interviews showed that the participants were in fact experimenting, even struggling, with different ways of team formations and the question of how to allocate their human resources, as admitted by a partner from one of the largest DCFs:

We don't have a clear organizational structure. It's a spaghetti structure. Increasingly we work together [with overseas offices] over the internet. Each office uses the resources of seven-eight other offices [...] We have an informal collaboration system. (Partner, Designit)

One of the DCFs worked with a professional project manager but had a hard time organizing design work in project management terms. Timesheets, coordination across projects, accounting of every activity seemed to be in odds with the laissez-faire way, long-hours and the relaxed culture of the design studio practice:

Designers have a very different way of working. It has not been easy for me so far. They put their heart and soul, and they treat the project as never ending. I try to explain to them that this is business, and no matter how much they work, we are only paid for certain hours. (Project Manager, Designit)

For designers, what lies beneath the surface of a problem is believed to unfold gradually as the project progresses. As such, each new interview, each new sketch, and each prototype could potentially lead to a totally new direction. Thus, project management tools were seen as restricting, and an up-front accounting for a project in management terms is perceived as a chore. Add to this that many interviewees described themselves as someone engaged in creative work who needed to 
be free. Also, designers apparently develop an emotional attachment to their projects, as they often referred to their projects as their baby, child, or signature, etc. This high level of emotional involvement with their work is perhaps another reason for the uneasy match between the management tools and design's work culture.

\subsection{Human-Centered Design}

User research often serves as a stepping stone for DCFs to get involved with strategy-level work. It brings user needs, problems and opportunities into focus. These may have to be addressed at the level of product, but may also call for changes at organizational processes, structure or even strategy. User research allows for an abstraction of the problem presented by the client-the task changes from designing a product to solving a problem identified from users' standpoint. That is, it paves the way for strategy-level discussion and solution seeking.

As designers typically treat even well-defined problems as ill-defined, they often begin to tackle any project by challenging assumptions and framing the problem in new ways. This study was no exception. A great deal of emphasis was given by all participating firms to uncovering latent user needs, altering client expectations, and setting up of the right brief. The assumption is that it is not possible to know from the beginning of a project what the real problem is, or what kind of offering will solve it. The real problem would be revealed only after research and hands-on exploration. Usercentered and participatory perspectives are therefore instrumental in resetting client expectations and bringing strategic issues to the table. As user research in early stages of design aims to understand everyday life and learn from what people actually do, value, and even dream of, to deliver unique value, the findings often have to do with what people care about. This allows for an abstraction of the problem presented by the client-i.e., the task changes from designing a product to solving a problem as identified from users' standpoint. This, in turn, paves the way for strategylevel discussion and solution seeking. DCFs reported several instances in which their clients approached them with a request for a specific product design, but following user research, designers concluded that there was no need for a new product at all. Ironic as it may seem, designers recommended not designing a product. Instead, they reorganized the existing client portfolio according to user needs, simplified the existing products or user interaction with products, and made changes in the brand message. Doing this was a matter of integrity and related to the emphasis designers placed on the identification of the right problem. It also was a way of communicating to their clients that DCFs are not limited to products, but the main task was to identify the underlying problem and provide solutions no matter how deep or what level it was.

As clients did not readily accept user research, DCFs often found themselves in a position to push for human-centered design:

They were terrified. We explain in the beginning, we show them that they need to see the whole. Still today I struggle. It's chaotic. When they approach design company, they think designers deal with aesthetics and form. (Anthropologist, CPH Design)

Some even wanted to skip the user research phase altogether, but the DCFs did it anyways until the client acknowledged the need for it. They viewed research as a waste of time, so the DCFs had to convince them that it is a necessary step in order to reduce the risk of product failure.

To convince their clients, all DCFs developed some illustrations-showing stages of the design process, milestones, so to speak, and the value each stage adds to the outcome. They communicated this to their clients, and most, if not all, made it available on their web sites. That is, they seem to have adopted a human-centered approach even towards their own clients. In addition to studying end-user needs, they also spend time analyzing their clients to understand internal challenges. This is done mostly through immersion in the client organization, collaborative brief development, and co-creative workshops. It is viewed as an essential part of the initial phase of the definition of the brief: 
You have to control the process. You have to understand what they [the clients] say, how they work and what they value. It is only then that you can help them to design the project. We have a process to ensure that we get it right. We start with a foundation day [...] It's about ensuring that the problem is right. (Partner, Designit)

Other DCFs too had clearly defined protocols in place that would supposedly help them understand their clients and show the direction the project should take. The design brief was drafted only after some progress has been made to understand the client's needs. Also, having to customize their protocols as needed was part of the work. For example, after realizing that clients tended not to trust the findings of ethnographic work, Red Associates decided to have the scalability of their key findings from ethnographic data verified through quantitative research — in collaboration with a marketing research firm. And it was not uncommon for DCFs to have different deliverables for different stakeholders within the same client organization. What mattered was to be able to manage the complexity of data and create a storyline that was understandable and clear enough for the relevant stakeholder to act upon:

They are business people. It is abstract to them. We present marinated data. We adopt doctor's perspective. We say: "Let me tell you a story about Sam." We prepare boards with photos of Sam, a dairy, a film. What we do is actually taking a theoretical model, show it to them graphically. When they see a model like that, they leave that day saying "That's interesting. How/what could it mean? This could lead us in this direction." (Partner, Red Associates)

With the arrival of human-centered design, DCFs added new tools and competencies to their portfolio. Social scientists joined the teams, and designers acquired new skills, including research, communication, process training, and organizational design. Commonly used tools in design such as visualization, prototyping and storytelling are utilized too in the making of strategy to visualize complex situations, problems, opportunities, and present and future strategies. For example, DN, in partnership with Elevated ApS, has developed a tool called BreakAway based on Kim and Mauborgne's (2005) blue ocean strategy. New forms of deliverables place more emphasis on the process, problem formulation, storytelling and value. Vertical integration also accompanies the human-centered design path to strategy work.

\section{Conclusion}

This study provided some initial insights into design's ways of expanding to new territories and engaging with questions of strategy. As it emerged from the data, DCFs get involved in strategy-level work in two distinct but related ways. First, as design firms work with the same clients over relatively long periods of time, they build client trust, as a result of which the complexity and strategic importance of their deliverables increase. Second, user-centered design provides a way for reframing problems and resetting client expectations, as well as addressing the key strategy question of what to do next. Both paths were characterized by new ways for DCFs to organize their own work and to relate to their clients. This expansion in activity area is accompanied by (1) horizontal value integration, where a range of diverse design services are offered as a bundle to clients, or (2) vertical value integration, where upstream and downstream activities are performed. Also, new competencies and skills such as research, business development and innovation training are adopted. The existing competencies, on the other hand, such as visualization, creative problem solving, etc., are adapted to the new situation. In their transition to strategic work, DCFs try hard to emphasize the process along with the product and communicate the value of their work to their clients along the way. Yet more research is needed to fully uncover how design makes its way to strategy formation. Specifically, future research needs to focus on the expansion of design in client organizations with varying organizational cultures and levels of design adoption. 


\section{References}

Andrews, K. R. (1980). Directors' responsibility for corporate strategy. Harvard Business Review, 58(6), 30-42.

Alvesson, M. (2011). De-essentializing the knowledge intensive firm: Reflections on sceptical research going against the mainstream. Journal of Management Studies, 48(7): 1640-1661.

Ansoff, H. I. (1965). Corporate Strategy. New York: McGraw Hill.

Barney, J. (1991) Firm resources and sustained competitive advantage. Journal of Management, 17(1), 99-120.

Blaich, R., \& Blaich, J. (1993) Product design and corporate strategy: Managing the connection for competitive advantage. New York: McGraw Hill.

Boland, R. J., \& Collopy, F. (Eds.). (2004), Managing as designing. Stanford, CA: Stanford University Press.

Borja de Mozota, B. (2011). Design strategic value revisited: A dynamic theory for design as organizational function. In R. Cooper, S. Junginger \& T. Lockwood (Eds.), The handbook of design management, (pp. 276293). Oxford: Berg.

Borja de Mozota, B., \& Kim, B. Y. (2009) Managing design as a core competency: Lessons from Korea. Design Management Review, 20(2), pp 67-76.

Boztepe, S. (2016). Design expanding into strategy: Evidence from design consulting firms. Design Research Society (DRS) 50th Anniversary Conference, Brighton, UK, June 27-30, 2016.

Brown, T. (2009). Change by design: How design thinking transforms organizations and inspires innovation. New York: Harper Collins.

Brown T., \& Martin, R. (2015). Design for action. Harvard Business Review, 93(9), 57-64.

Buchanan, R. (1992). Wicked problems in design thinking. Design Issues, 8(2), 5-21.

Buchanan, R. (2001). Design research and the new learning. Design Issues, 17, 3-23.

Cohen, M. D., March, J. G., \& Olsen, J. P. (1972). A garbage can model of organizational choice. Administrative Science Quarterly, 17(1), 1-25.

Cross, N., (1982). Designerly ways of knowing. Design Studies, 3(4), 221-227.

Cyert, R. M., \& March, J. G. (1992). A behavioral theory of the firm (2nd ed.). Englewood Cliffs: Prentice Hall.

Danish Design Center. (2001). Design staircase: Facts \& insights about design motivations and barriers. Copenhagen, Denmark.

Danish Design Center. (2016). Design delivers: How design accelerates your business. Copenhagen, Denmark.

Eames R. \& Eames, C. (Producer). (1972). Design Q\&A [Motion picture]. Retrieved from http://www.eamesoffice.com/the-work/design-q-a/

Dumas, A., \& Mintzberg, H. (1989). Managing design/designing management. Design Management Journal, 1(1), 37-43.

Eisenhardt, K. M., \& Martin, J. A. (2000) Dynamic capabilities: What are they? Strategic Management Journal, 21, 1105-1121.

Gardien, P., Djajadiningrat, T., Hummels, C., \& Brombacher, A. (2014). Changing your hammer: The implications of paradigmatic innovation for design practice. International Journal of Design, 8(2), 119-139.

Gornik, N. (2006). Convergence: New management imperatives and their effects on design. Design Management Review, 17(2), 35-43.

Heskett, J. (1985). Industrial Design. London: Thames \& Hudson.

Heskett, J. (2001). Research guidelines for investigating corporate design. [Handout]. Institute of Design, Illinois Institute of Technology.

Heskett, J.(2002). Toothpicks and logos. New York: Oxford University Press.

Heskett, J. (2017) Design and the creation of value. C. Dilnot \& S. Boztepe (Eds.). New York: Bloomsbury.

Jevnaker, B. H. (1998). Building up organizational capabilities in design. In M. Bruce \& B. H. Jevnaker (Eds.),

Management of design alliances: Sustaining competitive advantage (pp. 13-37). New York: Wiley.

Jones, J. C. (1970). Design methods. New York: Willey.

Julier, G. (2017). Economies of design. London: Sage.

Junginger, S. (2009). Design in organizations: Parts and wholes. Design Research Journal, 2(9): 23-29.

Kolko, J. (2015). Design thinking comes of age. Harvard Business Review, 93(9), 66-71.

Kotler, P., \& Rath, A. (1984). Design: A powerful but neglected strategic tool. Journal of Business Strategy, 5 (2), 16-21.

Levinthal, D. A. (2011). A behavioral approach to strategy-What's the alternative? Strategic Management Journal, 32(13), 1517-1523.

Liedtka, J. (2000). In defense of strategy as design. California Management Review, 42(3), pp 8-30.

Lojacono, G., \& Zaccai, G. (2004). The evolution of the design-inspired enterprise. Sloan Management Review, 45(3): 75-79. 
Lorenz, C. (1986). The design dimension. Cambridge, NA: Basil Blackwell.

Martin, R. L. (2009). The design of business: Why design thinking is the next competitive advantage. Boston, MA: Harvard Business Press.

Michlewski, K. (2015). Design attitude. London: Routledge.

Mintzberg, H. (1978). Patterns in strategy formation. Management Science, 24(9), 934-948.

Mintzberg, H., Waters, J. A. (1985). Of strategies, deliberate and emergent. Strategic Management Journal, 6(3), 257-272.

Mintzberg, H. (1994). The rise and fall of strategic planning. New York: Free Press.

Norman, D. (2016). When you come to a fork in the road, take it: The future of design. She Ji: The Journal of Design, Economics, and Innovation, 2(4), 343-348.

Porter, M. E. (1980). Competitive strategy: Techniques for analyzing industries and competitors. New York: Free Press.

Ravasi, D., \& Lojacono, G. (2005). Managing design and designers for strategic renewal. Long Range Planning, 38: $51-77$.

Schön, D. (1983). The reflective practitioner: How professionals think in action. New York: Basic Books.

Shivakumar, R. (2014). How to tell which decisions are strategic? California Management Review, 56(3): 78-97.

Simon, H. A. (1993) Strategy and organizational evolution. Strategic Management Journal, 14, 131-142.

Simon, H. A. (1996) The sciences of the artificial. Cambridge, MA: The MIT Press.

Svengren Holm, L. (2011) Design management as integrative strategy. In R. Cooper, S. Junginger \& T. Lockwood (Eds.), The handbook of design management (pp. 294-315). Oxford: Berg.

Squires, S., \& Byrne, B. (Eds.). (2002). Creating breakthrough ideas: The collaboration of anthropologists and designers in the product development industry. Westport, CT: Bergin \& Garvey.

Teece, D. J., Pisano, G., \& Shuen, A. (1997). Dynamic capabilities and strategic management. Strategic Management Journal, 18(7), pp 509-533.

Walsh, V., Roy, R., \& Bruce, M. (1988). Competitive by design. Journal of Marketing Management, 4(2), 201216.

Wernerfelt, B. (1984). A resource-based view of the firm. Strategic Management Journal, 5(2), pp 171-180.

About the Author:

Suzan Boztepe, Ph.D., is Senior Lecturer at Malmö University. Her research interests include generating economic value by design, design-oriented innovation and the strategic impact of design. 